\title{
Communication \\ Distribution of Interferon Lambda 4 Single Nucleotide Polymorphism rs11322783 Genotypes in Patients with COVID-19
}

\author{
Leonardo Sorrentino ${ }^{1}\left(\mathbb{D}\right.$, Valentina Silvestri ${ }^{2}{ }^{\mathbb{D}}$, Giuseppe Oliveto $^{1}$, Mirko Scordio ${ }^{1}$, Federica Frasca ${ }^{1}$, \\ Matteo Fracella ${ }^{1}$, Camilla Bitossi ${ }^{1}$, Alessandra D'Auria ${ }^{1}$, Letizia Santinelli ${ }^{3}$ (D) , Lucia Gabriele ${ }^{4}$ (D),

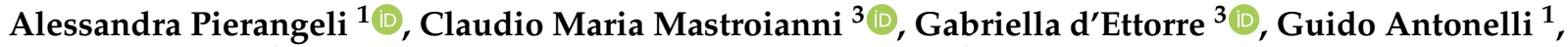 \\ Antonio Caruz $^{5}$ (D) , Laura Ottini ${ }^{2}$ and Carolina Scagnolari ${ }^{1, *(D)}$
}

Citation: Sorrentino, L.; Silvestri, V.; Oliveto, G.; Scordio, M.; Frasca, F.;

Fracella, M.; Bitossi, C.; D'Auria, A.; Santinelli, L.; Gabriele, L.; et al. Distribution of Interferon Lambda 4 Single Nucleotide Polymorphism rs11322783 Genotypes in Patients with COVID-19. Microorganisms 2022, 10, 363. https://doi.org/10.3390/ microorganisms10020363

Academic Editor: Graham H. Mitchell

Received: 31 December 2021

Accepted: 24 January 2022

Published: 4 February 2022

Publisher's Note: MDPI stays neutral with regard to jurisdictional claims in published maps and institutional affiliations.

Copyright: (C) 2022 by the authors. Licensee MDPI, Basel, Switzerland. This article is an open access article distributed under the terms and conditions of the Creative Commons Attribution (CC BY) license (https:// creativecommons.org/licenses/by/ $4.0 /)$.
1 Laboratory of Virology, Department of Molecular Medicine, Sapienza University of Rome, 00185 Rome, Italy; leonardo.sorrentino@uniroma1.it (L.S.); giuseppe.oliveto@uniroma1.it (G.O.); mirko.scordio@uniroma1.it (M.S.); federica.frasca@uniroma1.it (F.F.); matteo.fracella@uniroma1.it (M.F.); camilla.bitossi@uniroma1.it (C.B.); dauria.1698419@studenti.uniroma1.it (A.D.); alessandra.pierangeli@uniroma1.it (A.P.); guido.antonelli@uniroma1.it (G.A.)

2 Department of Molecular Medicine, Sapienza University of Rome, 00185 Rome, Italy; valentina.silvestri@uniroma1.it (V.S.); laura.ottini@uniroma1.it (L.O.)

3 Department of Public Health and Infectious Diseases, Sapienza University of Rome, Policlinico Umberto I of Rome, 00185 Rome, Italy; letizia.santinelli@uniroma1.it (L.S.); claudio.mastroianni@uniroma1.it (C.M.M.); gabriella.dettorre@uniroma1.it (G.d.)

4 Department of Oncology and Molecular Medicine, Istituto Superiore di Sanità, 00161 Rome, Italy; lucia.gabriele@iss.it

5 Immunogenetic Unit, Department of Experimental Biology, University of Jaén, 23071 Jaén, Spain; caruz@ujaen.es

* Correspondence: carolina.scagnolari@uniroma1.it

\begin{abstract}
Type III interferons (IFN-III), also known as IFN-Lambda, have a pivotal role during SARS$\mathrm{CoV}-2$ infection. IFN-Lambda response among individuals is heterogeneous and its association with COVID-19 symptoms severity needs to be further clarified. We analyzed the genotype frequencies of IFNL4 single nucleotide polymorphism (SNP) rs11322783 in patients with COVID-19 $(n=128)$, in comparison with a validated data set of European healthy controls $(n=14152)$. The IFNL4 SNP was also analyzed according to the haematological and clinical parameters of patients with COVID-19. The distributions of IFNL4 genotypes among SARS-CoV-2 positive patients [TT/TT 41.4\% $(n=53)$, TT/ $\Delta \mathrm{G}$ $47.7 \%(n=61)$ and $\Delta \mathrm{G} / \Delta \mathrm{G} 10.9 \%(n=14)]$ and healthy controls were comparable. Different levels of white blood cells $(p=0.036)$ and neutrophils $(p=0.042)$ were found in the IFNL4 different genotypes in patients with COVID-19; the $\Delta G / \Delta G$ genotype was more represented in the groups with low white blood cells and neutrophils. There were no differences in major inflammation parameters (Creactive protein, D-dimer, Albumin, and Lactate-dehydrogenase (LDH)] and survival rate according to the IFNL4 genotypes. In conclusion, although patients with COVID-19 did not exhibit a different distribution of the IFNL4 SNP, the $\Delta \mathrm{G} / \Delta \mathrm{G}$ genotype was associated with a lower count of immune cell populations. These findings need to be confirmed in larger groups of patients with COVID-19 and the role of IFNL4 SNP needs to be also investigated in other respiratory viral infections.
\end{abstract}

Keywords: COVID-19; IFN-Lambda4; single nucleotide polymorphism; rs11322783

\section{Introduction}

The interferon (IFN) response is the first line of defense against pathogens, including respiratory viruses. Two types of IFN are essential to "interfere" with the initial viral replication: type I IFN (IFN-I) and type III IFN (IFN-III), also known as IFN lambda (IFNL) [1,2]. Four IFNL subtypes have been found in humans: IFNL1 (IL-29), IFNL2 (IL-28A), IFNL3 (IL-28B), and IFNL4. IFNL4 shares only $~ 28 \%$ amino acid identity with the 
other IFNL genes, leading to speculation IFNL4 may have been introduced via a separate duplication event [1,2]. IFNLs are essential components of the mucosal innate immune response, with reported in vitro antiviral activity against respiratory viruses including highly pathogenetic coronaviruses, SARS-CoV-2 and MERS-CoV [1-5].

Genome-wide association studies have linked clearance of hepatitis $\mathrm{C}$ virus (HCV) to genetic variations within IFN-III loci [6], and this subsequently led to the discovery of the IFNL4 gene [7] Studies indicate that IFNL4 protein can induce IFN-stimulated genes (ISGs) through activation of the Janus kinase (JAK)-signal transducer and activator of transcription (STAT) pathway and exert antiviral effects [5,7]. Upon identification of the IFNL4 gene, Prokunina-Olsson et al. found a dinucleotide genetic variant (TT/TT, TT/ $\Delta \mathrm{G}$ or $\Delta \mathrm{G} / \Delta \mathrm{G}$ ), situated in the first exon of this gene [7]. Only individuals carrying the ancestral IFNL4$\Delta \mathrm{G}$ allele of the single nucleotide polymorphism (SNP) named rs368234815, now merged in rs11322783 [8], are able to synthesize the full-length functional IFNL4 protein [9]. By contrast, IFNL4 TT, leads to a frameshift and therefore to aborted expression of IFNL4 protein [7]; the allele frequency for IFNL4- $\Delta \mathrm{G}$ varies markedly by population (with a frequency of $95 \%$ in Africa, around 50\% in Europe, and 15\% in Asia) and seems to be under negative selection [7]. The rs11322783 SNP is in strong linkage disequilibrium with the genetic variation, SNP rs12979860, located within intron 1 of IFNL4 and associated with spontaneous and IFN therapy-induced HCV clearance [7,10-16]. In particular, carriers of the CC genotype at rs12979860 or of the TT genotype at rs11322783 are more likely to spontaneously clear acute HCV infection or to better respond to IFN treatments than individuals with rs12979860 T or rs11322783 $\Delta \mathrm{G}$ allele [7,10-16]. Given that the better response to $\mathrm{HCV}$ is probably not the evolutionary driver against the expression of IFNL4 protein [2], many studies in other infectious diseases have been conducted, but only a few reported associations with variants in the IFNL3 and IFNL4 region. Both the unfavourable rs11322783 $\Delta \mathrm{G}$ and rs12979860 T alleles were associated with impaired clearance of other RNA viruses, including Rhinovirus and Enterovirus [17]. In partial disagreement, our previous study in children bronchiolitis cases indicate that rs12979860 and rs8099917 SNPs had no impact on the clinical course of bronchiolitis with the only exception of the rs12979860 TT genotype which increased the risk of hospitalization for bronchiolitis at an earlier age [18].

As far as the impact of the IFNL4 SNPs in SARS-CoV-2 infection is concerned, Agwa et al. observed that the CC genotype in IFNL4 SNP rs12979860 is more frequent in patients with COVID-19 than in healthy controls in Egypt [19]. On the contrary, Saponi-Cortes et al. found that the rs12979860 T allele was associated with COVID-19 incidence in Spain [20]. Additionally, patients who simultaneously expressed IFNL4 SNP (rs11322783 TT/TT) and genotypes of other SNPs (rs12979860 CC, rs12980275 AA, rs8099917 TT) were associated to survivability to SARS-CoV-2 infection [19]. Moreover, SNP rs1297860 TT genotype and SNP rs11322783 $\Delta \mathrm{G} / \Delta \mathrm{G}$ genotype in patients with COVID-19 indicated a lower ability in SARS-CoV-2 clearance [21].

Remarkably, heterogeneous IFN-III responses in relationship with severity of COVID19 has been observed. Multiple studies found that reduced expression levels of IFN-III were associated with patients' worse outcomes, reducing SARS-CoV-2 clearance [22]. Our previous study showed a general decreased expression of IFNL1-3, IFN-I, and ISGs-mRNAs in critically ill patients with COVID-19 that required invasive mechanical ventilation [23]. In agreement, Sposito et al. reported that IFNL1, IFNL3, and ISGs expression is lower in patients with severe COVID-19 [24]. Moreover, a negative correlation between IFNL2 gene expression levels and severity of symptoms has been shown [19]. In this regard, the presence of IFNL4 SNPs has been associated with alterations in the expression level of IFN-III and ISGs [25-27]: subjects carrying CC genotype in rs1297860 SNP had a higher expression of ISGs, although T allele was associated with increased expression of IFN $\alpha$ and IFN $\beta$ [25]. However, data remains conflicting; indeed, ISGs expression is not influenced by the presence of rs11322783 $\Delta \mathrm{G}$ allele in HIV-1 infected patients [28]. More recently, Azim Ansari et al. found that expression of Angiotensin-converting enzyme 2 (ACE2), the 
functional receptor for SARS-CoV-2 entry into host target cells, is negatively correlated with IFNL4 production [29]. Remarkably, ACE2 transcripts' level (all isoforms) in vivo were correlated with those of ISG15, a marker of type I and III IFNs' activation in patients suffering from respiratory diseases not caused by SARS-CoV-2 [30].

Thus, in order to provide insight into the impact of the IFNL4 SNPs in SARS-CoV-2 infections, we investigated whether genotypes of rs11322783 SNP were differently distributed between patients with COVID-19 and the European validated group of healthy controls [31]. We also examined whether the presence of the $\Delta \mathrm{G}$ allele was associated with demographic and clinical data, as well as with the rate of intensive care unit (ICU) admission, and severe outcome of COVID-19.

\section{Methods}

\subsection{Study Group}

A total of 128 Caucasian patients ( $\geq 18$ years) were recruited at the Division of Infectious Diseases, Department of Public Health and Infectious Diseases, Hospital of Sapienza University of Rome (Italy) with laboratory-confirmed SARS-CoV-2 infection. Nasopharyngeal swabs were collected within 48 hours of hospital admission for SARS-CoV-2 detection. Our study was delineated by eligibility criteria shared by all enrolled participants. Inclusion criteria were as follows: (i) all individuals who provided informed consent prior to the start of study procedure; (ii) male and female adults $\geq 18$ years of age; (iii) diagnosis of SARS-CoV-2 at the day of hospital admission. Exclusion criteria were as follows: to have not signed the informed consent; pregnancy status, human immunodeficiency virus (HIV) infection, contraindications for taking blood samples.

All the hospitalized patients received therapeutic regimens including dexamethasone (6 mg a day), low molecular weight heparin for prophylaxis of deep vein thrombosis as recommended at the time by the Italian Society of Infectious Diseases [32] and standard of care treatments. Amongst all participants, demographic and clinical data were obtained from electronic medical records in the Hospital Electronic Information System. Variables considered for the study included: age, gender, admission and discharge date from the hospital, length of hospitalization; cardiovascular (CV) disease, haematological and inflammation parameters [count of blood immune cell, C-reactive protein, D-dimer, Albumin, Lactate-dehydrogenase (LDH)], thrombotic events, blood bacterial infection and bacterial pulmonary superinfection. A predictive model, Comorbidity, Age, Lymphocyte count and Lactate dehydrogenase (CALL), has been devised to estimate progression towards severe forms of COVID-19 with optimal sensitivity and specificity. [33]. The CALL score ranges from 4 (absence of comorbidity, age under 60 years, lymphocyte count over $1.0 \times 10^{9} / \mathrm{L}$, $\mathrm{LDH}$ under $250 \mathrm{U} / \mathrm{L}$ ) to 13 (presence of comorbidity, age over 60 years, lymphocyte count under $1.0 \times 10^{9} / \mathrm{L}$, LDH over $500 \mathrm{U} / \mathrm{L}$ ). Blood samples were collected from each patient during the hospitalization. The study was approved by the institutional review board (Ethics Committee of Umberto I General Hospital Rif. 5836, Prot. 0690/2021). All study participants gave written informed consent.

\subsection{IFNL4 Genotyping}

Viral RNA was extracted from nasopharyngeal swabs using the Versant SP 1.0 Kit (Siemens Healthcare Diagnostics, Milan, Italy). In particular, $10 \mu \mathrm{l}$ of extracted RNA was reverse-transcribed and simultaneously amplified using a real-time RT-PCR system (RealStar SARS-CoV-2 RT-PCR, Altona Diagnostics, Hamburg, Germany), targeting E and $\mathrm{S}$ genes of SARS-CoV-2. TaqMan probe specific for the $\mathrm{E}$ gene is labeled with FAM reporter, while TaqMan probe specific for the $\mathrm{S}$ gene is labeled with Cy5 reporter, as previously described [32]. Then, SNP genotyping was carried out on purified whole nucleic acids from blood samples (DNeasy Blood and Tissue Kit, QIAGEN, Milan, Italy) collected from all SARS-CoV-2 positive patients. Briefly, $100 \mu \mathrm{L}$ of blood sample were mixed with $20 \mu \mathrm{L}$ of Proteinase K and $100 \mu \mathrm{L}$ of PBS. Then, $200 \mu \mathrm{L}$ of AL buffer were added and incubated at 56 ${ }^{\circ} \mathrm{C}$ for 10 ' minutes. After the incubation, $200 \mu \mathrm{L}$ of $96 \%$ ethanol were added, and transferred 
to the spin column. A centrifugation at $8000 \mathrm{rpm}$ for 1 minute was performed and the flowthrough was discarded. Next, $500 \mu \mathrm{L}$ of AW1 buffer were added and after a centrifugation at $8000 \mathrm{rpm}$ for 1 minute; the flow-through was discarded and the same step was repeated with AW2 buffer performing a centrifugation for 2 minutes. Lastly, each column was eluted in $200 \mu \mathrm{L}$ of AE buffer. Genotyping allelic discrimination was performed by the TaqMan method (StepOne Plus Real-Time PCR System, A.B. Foster City, CA, USA) using specific primers for the amplification of the polymorphic sequence and two TaqMan-MGB probes (VIC and FAM) specific for each allele (Express program and Genotyping assay service Applied Biosystem) as previously reported [28]. In particular, TaqMan probe with FAM dye label recognized the wild type allele (TT) while the TaqMan probe with VIC dye label was complementary to the variant allele $(\Delta \mathrm{G})$. For one well, $5 \mu \mathrm{L}$ of individuals DNAs were added to a mixture of final volume of $15 \mu \mathrm{L}$ containing $10 \mu \mathrm{L}$ 2x Probes Master Mix, 1 $\mu \mathrm{L}$ of SNP mixture and $4 \mu \mathrm{L}$ of nuclease-free water. Allelic discrimination was evaluated according to the variation of reported dye fluorescence signals among genotypes clusters.

\subsection{Data Analysis}

Genotyping was conducted in a blinded fashion relative to patient characteristics. Before testing for SNP, samples were anonymized, and a unique randomly generated identification code was assigned to each record and the correspondent swab. Researchers performing genetic analyses were unable to identify patients at all stages, and no permanent record linking these data to patient IDs was produced. For the present study, we relied on genotype frequencies of IFNL4 single-nucleotide polymorphism rs11322783 from a validated data set of European healthy subjects $(n=14152)$ [31]. All data were analyzed, and graphs were generated using STATA software, version 17.0 (StataCorp LCC, College Station, TX, USA). All measurements were expressed as median (Range). The demographic and clinical characteristics of SARS-CoV-2-infected patients and healthy controls were compared using the Chi-squared test and Mann Whitney U test. Survivability analyses were performed according to Kaplan-Meier method and univariate Cox regression model. Tests for deviation from Hardy-Weinberg equilibrium and Armitage's trend tests were used to evaluate deviation between observed and expected frequencies for identification of unexpected population or genotyping biases in genetic frequencies of rs 11322783 SNP in the patients with COVID-19. A logistic regression model was used to determine the allele and genotypes distribution in patients stratified by white blood cells (WBC) and neutrophils groups (high, medium, low). A $p$-value below 0.05 was considered significant.

\section{Results}

\subsection{Clinical Features of SARS-CoV-2 Infected Patients}

We enrolled SARS-CoV-2-infected patients $(n=128)$, of which $49(38.3 \%)$ were female, with a median age of 64 years. Demographic and clinical features of patients with COVID19 are shown in Table 1 . The median length of hospitalization was 19 days (Range: 1-86). Amongst SARS-CoV-2-infected individuals, 24 (18.7\%) required Intensive Care Unit (ICU) admission because of pulmonary embolism. Moreover, 15 (11.7\%) cases had thrombotic events, $13(10.2 \%)$ had a bacterial blood infection and $12(9.4 \%)$ cases had bacterial pulmonary superinfection. Patients were stratified in three groups according to the CALL clinical score resulting in: $29(22.6 \%)$ with low CALL (4-6), $45(35.2 \%)$ with intermediate CALL (7-9) and 54 (42.2\%) with high CALL (10-13) severity score. 
Table 1. Demographic, clinical, and biochemical features of SARS-CoV-2 infected patients.

\begin{tabular}{|c|c|}
\hline Features & COVID-19 Patients $(n=128)$ \\
\hline Age at diagnosis (years) (mean (range)) & $63.9(25-95)$ \\
\hline \multicolumn{2}{|l|}{ Gender (N (percentage)) } \\
\hline Male & $79(61.7)$ \\
\hline Female & $49(38.3)$ \\
\hline \multicolumn{2}{|l|}{ CALL score (N (percentage)) } \\
\hline Low severity (4-6) & $29(22.6)$ \\
\hline Intermediate severity (7-9) & $45(35.2)$ \\
\hline High severity (10-13) & $54(42.2)$ \\
\hline \multicolumn{2}{|l|}{ Clinical features ( $\mathrm{N}$ (percentage)) } \\
\hline ICU & $24(18.7)$ \\
\hline Thrombotic events & $15(11.7)$ \\
\hline Death & $21(16.4)$ \\
\hline BSI & $13(10.2)$ \\
\hline Bacterial pulmonary superinfection & $12(9.4)$ \\
\hline \multicolumn{2}{|l|}{ Blood parameters (mean (range)) } \\
\hline $\mathrm{WBC}$ cell $/ \mathrm{mm}^{3}$ & $6293.6(2110-19150)$ \\
\hline Neutrophils cell $/ \mathrm{mm}^{3}$ & $4691.2(1120-18000)$ \\
\hline Lymphocytes cell $/ \mathrm{mm}^{3}$ & $1067.7(110-4760)$ \\
\hline Monocytes cell $/ \mathrm{mm}^{3}$ & $361.7(150-1040)$ \\
\hline $\mathrm{CRP} \mu \mathrm{g} / \mathrm{L}$ & $98380(300-540000)$ \\
\hline D-dimer $\mu \mathrm{g} / \mathrm{L}$ & $1690(176-4610)$ \\
\hline Albumin g/L & $36.9(19-46)$ \\
\hline $\mathrm{LDH} \mathrm{U/L}$ & $335(111-1249)$ \\
\hline Platelets cell $/ \mathrm{mm}^{3}$ & $221 \times 10^{3}(65-516)$ \\
\hline
\end{tabular}

ICU: intensive care unit; BSI: bloodstream infections; WBC: white blood cells; CRP: C-reactive protein; LDH: lactate dehydrogenase.

\subsection{IFNL4 SNPs in Patients with COVID-19}

The frequencies of IFNL4 rs11322783 genotypes in the patients with COVID-19 $(n=128)$ and a validated data set of European healthy controls $(n=14152)$ [31] were as follows: TT $/ \mathrm{TT} 41.4 \%(n=53)$ vs. $45 \%$, TT $/ \Delta \mathrm{G} 47.7 \%(n=61)$ vs. $44.2 \%$ and $\Delta \mathrm{G} / \Delta \mathrm{G} 10.9 \%(n=14)$ vs. $10.8 \%$; there was no statistically significant difference in the distribution of IFNL4 genotypes ( $p>0.05$ for all the measurements). Then, we evaluated whether the distribution of the IFNL4 rs11322783 genotypes in patients with COVID-19 varied according to the count of blood immune cells (total white blood cells number, neutrophils, lymphocytes, monocytes, platelets), levels of inflammation parameters (C-reactive protein, D-dimer, Albumin and LDH), and the rate of ICU admission, thrombotic events, blood bacterial infection (caused by E. coli, S. epidermidis, E. faecalis, S. aureus, A. baumannii and S. hominis), and bacterial pulmonary superinfection (caused by P. aeruginosa and K. pneumoniae). Different levels of white blood cells (WBC) $(p=0.036)$ and neutrophils $(p=0.042)$ were found in patients with COVID-19 among the three different genotypes (Table 2). In addition, the logistic regression model used to determine the allele distribution in the groups (medium, high, low), showed that the $\Delta G / \Delta G$ genotype was significantly more represented in those with lower WBC and neutrophils (Table 3).

No other statistically significant relationships were observed for the remaining studied variables concerning the IFNL4 genotypes.

\subsection{Survival Analysis in Patients with COVID-19}

Survival analysis showed that IFNL4 rs11322783 genotype distribution was not associated with patients' outcome (Figure 1, Panel A). Moreover, survival analysis revealed no significant differences according to the age, gender, and the CALL score assigned to each COVID-19 patient (Figure 1, Panel B). As expected, those patients transferred to ICU $(p=0.001)$ or with bloodstream infections (BSI, $p=0.018)$ had a worse overall survival outcome compared to those not admitted to ICU and without BSI (Figure 1, Panel C and D). 
Table 2. Correlation between IFNL4 genotypes with counts blood immune cells, levels of inflammation parameters, and COVID-19 outcomes.

\begin{tabular}{|c|c|c|c|c|c|}
\hline Features & Ranges* & IFNL4 SNP TT/TT & IFNL4 SNP $\Delta \mathrm{G} / \mathrm{TT}$ & IFNL4 SNP $\Delta \mathrm{G} / \Delta \mathrm{G}$ & $p$-Value \\
\hline \multirow{2}{*}{ SARS-CoV-2 patients } & & $53(41.4)$ & $61(47.7)$ & $14(10.9)$ & \\
\hline & $4.5-11.0 \times 10^{3}$ & $40(75.5)$ & $52(86.7)$ & $7(50.0)$ & \\
\hline \multirow[t]{3}{*}{$\mathrm{WBC}$ cell $/ \mathrm{mm}^{3}$} & $<4.5 \times 10^{3}$ & $7(13.2)$ & $5(8.3)$ & $5(35.7)$ & 0.036 \\
\hline & $>11.0 \times 10^{3}$ & $6(11.3)$ & $3(5.0)$ & $2(14.3)$ & \\
\hline & $1.5-8.0 \times 10^{3}$ & $43(81.1)$ & $52(86.6)$ & $8(57.1)$ & \\
\hline \multirow[t]{3}{*}{ Neutrophils cell $/ \mathrm{mm}^{3}$} & $<1.5 \times 10^{3}$ & $3(5.7)$ & $4(6.7)$ & $4(28.6)$ & 0.042 \\
\hline & $>8.0 \times 10^{3}$ & $7(13.2)$ & $4(6.7)$ & $2(14.3)$ & \\
\hline & $1.0-4.0 \times 10^{3}$ & $43(81.1)$ & $50(83.3)$ & $10(71.4)$ & \\
\hline \multirow[t]{3}{*}{ Lymphocytes cell $/ \mathrm{mm}^{3}$} & $<1.0 \times 10^{3}$ & $10(18.9)$ & $10(16.7)$ & $4(28.6)$ & 0.59 \\
\hline & $>4.0 \times 10^{3}$ & - & - & - & \\
\hline & $0.1-0.7 \times 10^{3}$ & $49(92.4)$ & $60(98.4)$ & $14(100)$ & \\
\hline \multirow[t]{2}{*}{ Monocytes cell $/ \mathrm{mm}^{3}$} & $<0.1 \times 10^{3}$ & $3(5.7)$ & $1(1.6)$ & $0(0.0)$ & 0.47 \\
\hline & $>0.7 \times 10^{3}$ & $1(1.9)$ & $0(0.0)$ & $0(0.0)$ & \\
\hline \multirow{2}{*}{$\mathrm{CRP} \mu \mathrm{g} / \mathrm{L}$} & $<8.0 \times 10^{3}$ & $8(15.1)$ & $6(9.8)$ & $3(21.4)$ & \\
\hline & $>8.0 \times 10^{3}$ & $45(84.9)$ & $55(90.2)$ & $11(78.6)$ & 0.45 \\
\hline \multirow{3}{*}{ D-dimer $\mu \mathrm{g} / \mathrm{L}$} & $<500$ & 5 (11.4) & $9(16.4)$ & $2(14.3)$ & \\
\hline & $>500$ & $39(88.6)$ & $46(83.6)$ & $12(85.7)$ & 0.78 \\
\hline & $35-55$ & $30(66.7)$ & $30(53.6)$ & $8(61.5)$ & \\
\hline \multirow[t]{3}{*}{ Albumin $\mathrm{g} / \mathrm{L}$} & $<35$ & $15(33.3)$ & $26(46.4)$ & $5(38.5)$ & 0.41 \\
\hline & $>55$ & - & - & - & \\
\hline & $80-300 \times 10^{3}$ & $16(38.8)$ & $21(35.0)$ & $4(28.6)$ & \\
\hline \multirow[t]{3}{*}{$\mathrm{LDH} \mathrm{U/L}$} & $<80 \times 10^{3}$ & $4(7.7)$ & $1(1.7)$ & $0(0.0)$ & 0.47 \\
\hline & $>300 \times 10^{3}$ & $32(61.5)$ & $38(63.3)$ & $10(71.4)$ & \\
\hline & $150-450 \times 10^{3}$ & $44(83.0)$ & $45(76.3)$ & $12(85.7)$ & \\
\hline \multirow[t]{3}{*}{ Platelets cell $/ \mathrm{mm}^{3}$} & $<150 \times 10^{3}$ & $7(13.2)$ & $12(20.3)$ & $2(14.3)$ & 0.8 \\
\hline & $>450 \times 10^{3}$ & $2(3.8)$ & $2(3.4)$ & $0(0.0)$ & \\
\hline & Low severity (4-6) & $13(24.6)$ & $13(21.3)$ & $3(21.4)$ & \\
\hline \multirow[t]{2}{*}{ Call } & Intermediate severity & $20(37.7)$ & $20(32.8)$ & $5(35.7)$ & 0.94 \\
\hline & High severity (10-13) & $20(37.7)$ & $28(45.9)$ & $6(42.9)$ & \\
\hline \multirow{2}{*}{ ICU admission rate } & yes & $11(20.7)$ & $11(18.0)$ & $2(14.3)$ & \\
\hline & no & $42(79.3)$ & $50(82.0)$ & $12(85.7)$ & 0.84 \\
\hline \multirow{2}{*}{ Thrombotic events } & Positive & $5(9.4)$ & $8(13.3)$ & $2(14.3)$ & \\
\hline & Negative & $48(90.6)$ & $52(86.7)$ & $12(85.7)$ & 0.78 \\
\hline \multirow{2}{*}{$\begin{array}{l}\text { Bloodstream infections } \\
\text { (BSI) }\end{array}$} & Positive & $6(11.8)$ & $6(10.7)$ & $1(7.7)$ & \\
\hline & Negative & $45(88.2)$ & $50(89.3)$ & $13(92.3)$ & 0.91 \\
\hline \multirow{2}{*}{$\begin{array}{l}\text { Bacterial pulmonary } \\
\text { superinfections }\end{array}$} & Positive & $6(12.2)$ & $4(7.3)$ & $2(15.4)$ & \\
\hline & Negative & $43(87.8)$ & $51(92.7)$ & $11(84.6)$ & 0.57 \\
\hline
\end{tabular}

Data are represented as total numbers (percentage) of SARS-CoV-2 patients grouped by IFNL4 genotypes. Statistical analyses were performed using Chi square test. In bold are represented significative $p$-values. * For WBC, neutrophils, lymphocytes, monocytes, albumin, LDH and platelets, normal, low and high levels are shown respectively. For CRP and D-dimer, normal and high levels are shown, respectively.

Table 3. Differences in IFNL4 allele and genotype frequencies among normal and abnormal ranges of WBC and neutrophils in SARS-CoV-2 patients.

\begin{tabular}{|c|c|c|c|c|c|c|c|}
\hline & & & $\begin{array}{c}\text { Allele } \\
\text { Frequencies } \\
\text { Comparison }\end{array}$ & $\begin{array}{c}\text { Heterozygous } \\
\text { and } \\
\text { Homozygous } \\
\text { Comparison }\end{array}$ & $\begin{array}{l}\text { Homozygous } \\
\text { and } \\
\text { Homozygous } \\
\text { Comparison }\end{array}$ & $\begin{array}{c}\text { Allele } \\
\text { Positivity } \\
\text { Comparison }\end{array}$ & $\begin{array}{l}\text { Armitage's } \\
\text { Trend Test }\end{array}$ \\
\hline \multirow{4}{*}{ WBC } & Normal levels & allele T & 0.22 & 0.33 & 0.04 & 0.95 & 0.20 \\
\hline & vs. low levels & allele $\Delta \mathrm{G}$ & 0.22 & 0.003 & 0.04 & 0.005 & 0.20 \\
\hline & Normal levels & allele T & 0.89 & 0.18 & 0.48 & 0.37 & 0.88 \\
\hline & vs. high levels & allele $\Delta \mathrm{G}$ & 0.89 & 0.08 & 0.48 & 0.20 & 0.88 \\
\hline \multirow{4}{*}{ Neutrophils } & Normal levels & allele T & 0.04 & 0.90 & 0.01 & 0.35 & 0.04 \\
\hline & vs. low levels & allele $\Delta \mathrm{G}$ & 0.04 & 0.01 & 0.01 & 0.003 & 0.04 \\
\hline & Normal levels & allele T & 0.82 & 0.25 & 0.63 & 0.41 & 0.81 \\
\hline & vs. high levels & allele $\Delta \mathrm{G}$ & 0.82 & 0.19 & 0.63 & 0.36 & 0.81 \\
\hline
\end{tabular}

Data are shown as $p$-values calculated with test for association. Test for deviation from Hardy-Weinberg equilibrium (data not shown) showed no significative differences $(p>0.05)$. WBC: white blood cells. 
Panel A

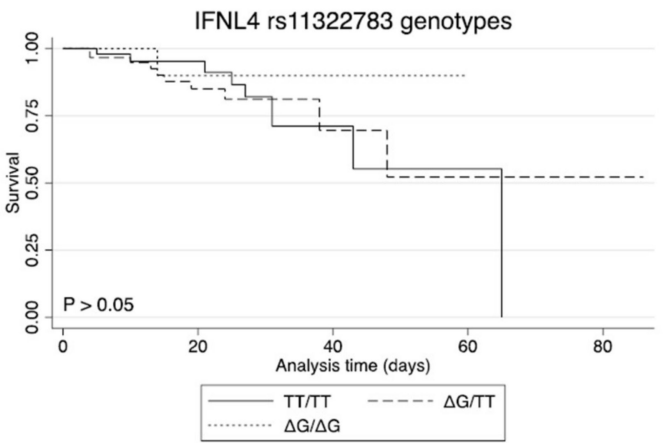

Panel C

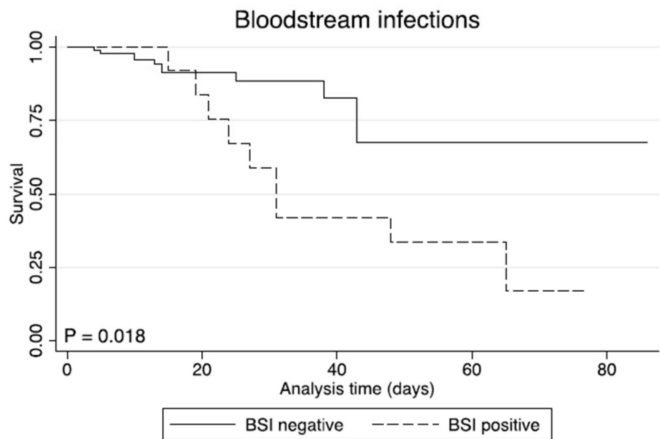

Panel B

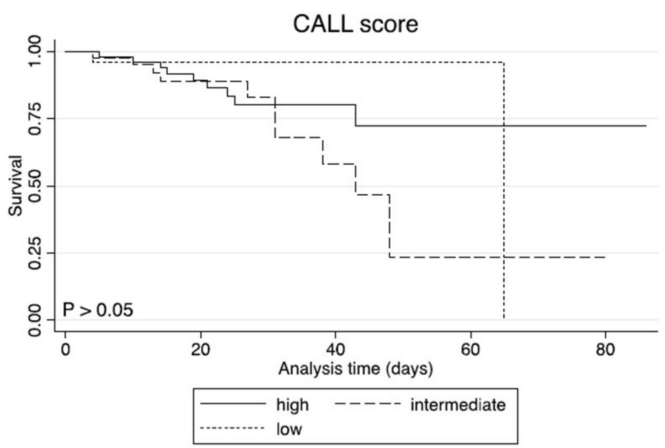

Panel D

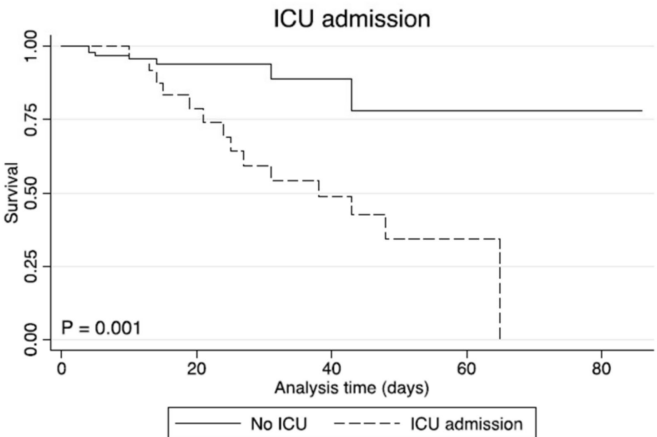

Figure 1. Survival rate according to IFNL4 rs11322783 SNP and clinical parameters in patients with COVID-19 by Kaplan-Meier Plotter. Survival Kaplan-Meier curves according with TT/TT, $\Delta$ G/TT and $\Delta \mathrm{G} / \Delta \mathrm{G}$ genotypes $(p>0.05$, Panel (A)), CALL score categories $(p>0.05$, Panel $(\mathbf{B}))$, the presence of BSI $(p=0.018$, Panel $(\mathbf{C}))$, and ICU admission $(p=0.001$, Panel (D)).

\section{Discussion}

IFN-III represents the most recently discovered members of the IFN system. Similar to IFN-I, IFN-Ls participate in defense against viruses mostly on cells of epithelial origin such as bronchial epithelium, gastrointestinal epithelium, and keratinocytes, according to the limited tropism of IFN-III receptor [1,2]. Moreover, as proof of the key role of IFN-III in the regulation of antiviral immunity, SNPs in IFNL4 loci were associated with clinical outcomes of different viral infections including those caused by SARS-CoV-2 [17,19,21].

In this study, we analyzed the distribution of the IFNL4 rs11322783 SNP in hospitalized SARS-CoV-2 infected patients. Our results indicate that rs11322783 IFNL4 genotypes are similarly distributed between patients with COVID-19 and healthy controls. Moreover, the IFNL4 SNP seems to not influence the clinical outcome of COVID-19 being not related to clinical severity (CALL score or ICU admission) and patients' survival outcomes. IFNLs are known to play a pivotal function during respiratory infections, including those caused by Respiratory Syncytial Virus (RSV) [34], Influenza A [35], and also SARS-CoV-2 [36]. IFN-III proper activation may control SARS-CoV-2 replication, promoting virus clearance and impairing progression to severe forms of COVID-19 [36]; an heterogenous response has been documented in patients with COVID-19, according to their clinical status [22,23]. The IFNL4 producing $\Delta \mathrm{G} / \Delta \mathrm{G}$ genotype has been associated with higher viral loads in patients with COVID-19 [37], but its contribution remains controversial [19,20]. Indeed, individuals who carry CC genotype of SNP rs12979860 showed a higher incidence of COVID-19 compared to the others [19]. On the other hand, the T allele of rs12979860 was overrepresented in patients with COVID-19 with regard to the general healthy population, indicating that this allele could be a risk factor for COVID-19 [20]. In this context, the CC genotype (rs12979860) was significantly lower in patients with COVID-19 compared to healthy controls [20], underlining the increasing complexity of this immunoregulatory network. 
In this study, we found different levels of total WBC and neutrophils among IFNL4 SNP genotypes; in particular, patients with COVID-19 homozygous for the IFNL4-producing allele were more represented in the group with low-counts of WBC and neutrophils.

Lymphopenia and higher levels of neutrophils and WBC have been frequently reported as markers of disease severity and mortality in COVID-19 [33]. Moreover, it is known that during early phases of viral infection, neutrophils are recruited from the circulation into the infectious site, and promote oxidative damage, phagocytosis, and virus clearance [38]. In this regard, an additional antimicrobial/antiviral function of neutrophils relies on a special type of programmed cell death called neutrophil extracellular traps (NETs) formation [39]. These NETs correspond to extracellular filaments of uncondensed chromatin (an association of DNA and histones) covered by numerous proteins of mainly granular origin [40]. An abnormal formation of NETs has been observed during severe COVID-19 and has been shown to contribute to lung damage and worse outcome of SARS-CoV-2 infection [41]. Increased plasma NET levels were observed in non-intubated patients with COVID-19, as well as in endotracheally intubated patients with COVID-19, compared with healthy donors and convalescent patients [42,43]. Accordingly, it has been demonstrated that SARS-CoV-2 is able to activate NETosis and increase levels of intracellular Reactive Oxygen Species (ROS) in human neutrophils [44]. In this study, patients with $\Delta \mathrm{G} / \Delta \mathrm{G}$ genotype presented lower levels of neutrophils and white blood cells that could influence the outcome of COVID-19. Indeed, during the early phase of SARS-CoV-2 infection, innate immunity, including that associated with IFN-I [45] and III [46] response, might control the viral spreading, limiting the rate of SARS-CoV-2 replication in the upper respiratory tract. Moreover, COVID-19 severe forms are characterized by the so-called "cytokine storm" and increased levels of neutrophils $[47,48]$. Formation of NETs can induce the production of IL1 $\beta$ by macrophages, and, simultaneously, IL1 $\beta$ can induce NETs formation [49] generating an IL1 $\beta$-NETs loop. At the same time, neutrophils express stable IFN-L receptor (IFNLR) [50] and produce ISGs during bacterial and viral infections [51,52]. It has been reported that deregulated expression of ISGs in neutrophils during acute respiratory distress syndrome (ARDS) is associated with worst outcome [51]. However, mice treated with IFN-L had reduced migratory capacity of neutrophils in tissues. Indeed, it has been shown that IFN-L treatment reduces neutrophils infiltration in arthritis [50] and these data was further confirmed in mice with the observation of a lower migration of neutrophils in gut during autoimmune diseases after treatment with IFN-L [53]. However, it remains unclear whether IFNL4 can regulate neutrophil response and its impact on neutrophil functions and related IFN-III pathways in COVID-19 individuals. Indeed, we did not find any differences in TT/ $\Delta G$ and TT/TT frequencies based on neutrophils and WBC levels (Table 3). Moreover, genomewide association studies (GWAS) did not find any correlations between IFNL4 SNP and COVID-19 [54-56], suggesting that IFNL4 SNP might have a small or no impact during SARS-CoV-2 infection. The latter aspect needs to be further investigated in a higher number of patients with COVID-19; indeed, a previous study [21] found that the $\Delta \mathrm{G} / \Delta \mathrm{G}$ genotype, in an Iranian population suffering from COVID-19, is associated with low survivability. Our results suggest that the role of IFNL4 in respiratory viral infections, including that caused by SARS-CoV-2, deserves to be better characterized.

Author Contributions: Conceptualization, C.S., G.d., G.A., L.O. and L.S (Leonardo Sorrentino); methodology, G.O., M.S., F.F. and L.S. (Letizia Santinelli); validation, V.S., L.O. and A.P.; formal analysis, L.S. (Leonardo Sorrentino), F.F., M.F., C.B. and A.D.; investigation, V.S., G.O., M.S., F.F., M.F., C.B., A.D. and L.S. (Letizia Santinelli); resources, C.S. and L.G.; data curation, L.S.; writing-original draft preparation, L.S., C.S. and A.P.; writing-review and editing, C.S., A.P. and A.C.; supervision, G.A., C.M.M., L.G. and G.d.; funding acquisition, G.A., L.G. and C.S. All authors have read and agreed to the published version of the manuscript.

Funding: This research was funded by a grant from the Italian Ministry of Health (COVID-202012371817) and a grant from Sapienza University (ATENEO H2020, PH120172B4BA8CAF) to G.A.; grants from Sapienza University (ATENEO RM120172B29590C6 and RM12117A513C1DDD) to C.S.; a grant from Intesa Sanpaolo (Project B/2020/0128 Fondo di Beneficenza) to L.G. 
Institutional Review Board Statement: The study was conducted in accordance with the Declaration of Helsinki, and approved by the Institutional Review Board (or Ethics Committee) of Umberto I General Hospital Rif. 5836, Prot. 0690/2021.

Informed Consent Statement: Informed consent was obtained from all subjects involved in the study. Data Availability Statement: Not applicable.

Acknowledgments: We would like to thank members of Diagnostic Department, nurses and physicians of the Infectious Disease Clinics, Umberto I Hospital.

Conflicts of Interest: The authors declare no conflict of interest.

\section{References}

1. Kotenko, S.V.; Rivera, A.; Parker, D.; Durbin, J.E. Type III IFNs: Beyond antiviral protection. Sem. Immunol. $2019,43,101303$. [CrossRef] [PubMed]

2. O'Brien, T.R.; Prokunina-Olsson, L.; Donnelly, R.P. IFN- $\lambda 4$ : The paradoxical new member of the interferon lambda family. J. Interferon Cytokine Res. 2014, 34, 829-838. [CrossRef] [PubMed]

3. Lazear, H.M.; Schoggins, J.W.; Diamond, M.S. Shared and distinct functions of type i and type iii interferons. Immunity 2019, 50, 907-923. [CrossRef] [PubMed]

4. Busnadiego, I.; Fernbach, S.; Pohl, M.O.; Karakus, U.; Huber, M.; Trkola, A.; Stertz, S.; Hale, B.G. Antiviral activity of type I, II, and III interferons counterbalances ace2 inducibility and restricts SARS-CoV-2. MBio 2020, 11, e01928-20. [CrossRef]

5. Jeon, Y.J.; Gil, C.H.; Jo, A.; Won, J.; Kim, S.; Kim, H.J. The influence of interferon-lambda on restricting Middle East Respiratory Syndrome Coronavirus replication in the respiratory epithelium. Antiviral Res. 2020, 180, 104860. [CrossRef]

6. Ge, D.; Fellay, J.; Thompson, A.J.; Simon, J.S.; Shianna, K.V.; Urban, T.J.; Heinzen, E.L.; Qiu, P.; Bertelsen, A.H.; Muir, A.J.; et al. Genetic variation in IL28B predicts hepatitis C treatment-induced viral clearance. Nature 2009, 461, 399-401. [CrossRef]

7. Prokunina-Olsson, L.; Muchmore, B.; Tang, W.; Pfeiffer, R.M.; Park, H.; Dickensheets, H.; Hergott, D.; Porter-Gill, P.; Mumy, A.; Kohaar, I.; et al. A variant upstream of IFNL3 (IL28B) creating a new interferon gene IFNL4 is associated with impaired clearance of hepatitis C virus. Nat. Genet. 2013, 45, 164-171. [CrossRef]

8. National Center for Biotechnology. 2021. Available online: https:/ /www.ncbi.nlm.nih.gov/snp/rs368234815?vertical_tab=true (accessed on 30 December 2021).

9. Noureddin, M.; Rotman, Y.; Zhang, F.; Park, H.; Rehermann, B.; Thomas, E.; Liang, T.J. Hepatic expression levels of interferons and interferon-stimulated genes in patients with chronic hepatitis C: A phenotype-genotype correlation study. Genes Immun. 2015, 16, 321-329. [CrossRef]

10. Palmieri, O.; Ippolito, A.M.; Margaglione, M.; Valvano, M.R.; Gioffreda, D.; Fasano, M.; D’Andrea, G.; Corritore, G.; Milella, M.; Andriulli, N.; et al. Variation in genes encoding for interferon $\lambda-3$ and $\lambda-4$ in the prediction of HCV- 1 treatment-induced viral clearance. Liver Int. 2014, 34, 1369-1377. [CrossRef]

11. Melis, R.; Fauron, C.; McMillin, G.; Lyon, E.; Shirts, B.; Hubley, L.M.; Slev, P.R. Simultaneous genotyping of rs12979860 and rs8099917 variants near the IL28B locus associated with HCV clearance and treatment response. J. Mol. Diagn. 2011, 13, 446-451. [CrossRef]

12. Sharafi, H.; Moayed Alavian, S.; Behnava, B.; Pouryasin, A.; Keshvari, M. The impact of IFNL4 rs12979860 polymorphism on spontaneous clearance of hepatitis c; a case-control study. Hepat Mon. 2014, 14, 10. [CrossRef]

13. Lapiński, T.W.; Pogorzelska, J.; Kowalczuk, O.; Nikliński, J.; Flisiak, R. SNP RS12979860 related spontaneous clearance of hepatitis c virus infection in HCV/HIV-1 coinfected patients. Przegl Epidemiol. 2013, 67, 12-16.

14. Franco, S.; Aparicio, E.; Parera, M.; Clotet, B.; Tural, C.; Martinez, M.A. IFNL4 ss469415590 variant is a better predictor than rs12979860 of pegylated interferon-alpha/ribavirin therapy failure in hepatitis C virus/HIV-1 coinfected patients. AIDS 2014, 28, 133-136. [CrossRef]

15. Lin, C.Y.; Chen, J.Y.; Lin, T.N.; Jeng, W.J.; Huang, C.H.; Huang, C.W.; Chang, S.W.; Sheen, I.S. IL28B SNP rs12979860 is a critical predictor for on-treatment and sustained virologic response in patients with hepatitis $\mathrm{C}$ virus genotype-1 infection. PLoS ONE 2011, 6, e18322. [CrossRef] [PubMed]

16. Griffiths, S.J.; Dunnigan, C.M.; Russell, C.D.; Haas, J.G. The role of interferon- $\lambda$ locus polymorphisms in Hepatitis C and other infectious diseases. J. Innate Immun. 2015, 7, 231-242. [CrossRef] [PubMed]

17. Rugwizangoga, B.; Andersson, M.E.; Kabayiza, J.C.; Nilsson, M.S.; Ármannsdóttir, B.; Aurelius, J.; Nilsson, S.; Hellstrand, K.; Lindh, M.; Martner, A. IFNL4 genotypes predict clearance of RNA viruses in rwandan children with upper respiratory tract infections. Front. Cell Infect Microbiol. 2019, 9, 340. [CrossRef]

18. Scagnolari, C.; Midulla, F.; Riva, E.; Monteleone, K.; Solimini, A.; Bonci, E.; Cangiano, G.; Papoff, P.; Moretti, C.; Pierangeli, A.; et al. Evaluation of interleukin 28B single nucleotide polymorphisms in infants suffering from bronchiolitis. Virus Res. 2012, 165, 236-240. [CrossRef]

19. Agwa, S.H.A.; Kamel, M.M.; Elghazaly, H.; Abd Elsamee, A.M.; Hafez, H.; Girgis, S.A.; Elarab, H.E.; Ebeid, F.S.E.; Sayed, S.M.; Sherif, L.; et al. Association between interferon-lambda-3 rs12979860, tll1 rs17047200 and ddr1 rs4618569 variant polymorphisms with the course and outcome of SARS-CoV-2 patients. Genes 2021, 12, 830. [CrossRef] 
20. Saponi-Cortes, J.M.R.; Rivas, M.D.; Calle-Alonso, F.; Sanchez, J.F.; Costo, A.; Martin, C.; Zamorano, J. IFNL4 genetic variant can predispose to COVID-19. Sci. Rep. 2021, 11, 10-27. [CrossRef] [PubMed]

21. Rahimi, P.; Tarharoudi, R.; Rahimpour, A.; Mosayebi Amroabadi, J.; Ahmadi, I.; Anvari, E.; Siadat, S.D.; Aghasadeghi, M.; Fateh, A. The association between interferon lambda 3 and 4 gene single-nucleotide polymorphisms and the recovery of COVID-19 patients. Virol. J. 2021, 18, 221. [CrossRef]

22. Yosuke, F.; Homma, T.; Inoue, H.; Onitsuka, C.; Ikeda, H.; Goto, Y.; Sato, Y.; Kimura, T.; Hirai, K.; Ohta, S.; et al. Downregulation of type III interferons in patients with severe COVID-19. J. Med. Virol. 2021, 93, 4559-4563.

23. Scagnolari, C.; Pierangeli, A.; Frasca, F.; Bitossi, C.; Viscido, A.; Oliveto, G.; Scordio, M.; Mazzuti, L.; di Carlo, D.; Gentile, M.; et al. Differential induction of type I and III interferon genes in the upper respiratory tract of patients with coronavirus disease 2019 (COVID-19). Virus Res. 2021, 295, 198283. [CrossRef] [PubMed]

24. Sposito, B.; Broggi, A.; Pandolfi, L.; Crotta, S.; Clementi, N.; Ferrarese, R.; Sisti, S.; Criscuolo, E.; Spreafico, R.; Long, J.M.; et al. The interferon landscape along the respiratory tract impacts the severity of COVID-19. Cell 2021, 184, 4953-4968. [CrossRef] [PubMed]

25. Raglow, Z.; Thoma-Perry, C.; Gilroy, R.; Wan, Y.J.Y. IL28B genotype and the expression of ISGs in normal liver. Liver Int. 2013, 33, 991-998. [CrossRef]

26. Rosenberg, B.R.; Freije, C.A.; Imanaka, N.; Chen, S.T.; Eitson, J.L.; Caron, R.; Uhl, S.A.; Zeremski, M.; Talal, A.; Jacobson, I.M.; et al. Genetic variation at IFNL4 influences extrahepatic interferon-stimulated gene expression in chronic HCV patients. J. Infect. Dis. 2018, 217, 650-655. [CrossRef]

27. Knapp, S.; Meghjee, N.; Cassidy, S.; Jamil, K.; Thursz, M. Detection of allele specific differences in IFNL3 (IL28B) mRNA expression. BMC Med. Genet. 2014, 15, 104. [CrossRef]

28. Monteleone, K.; Scheri, G.C.; Statzu, M.; Selvaggi, C.; Falasca, F.; Giustini, N.; Mezzaroma, I.; Turriziani, O.; d’Ettorre, G.; Antonelli, G.; et al. IFN-stimulated gene expression is independent of the IFNL4 genotype in chronic HIV-1 infection. Arch. Virol. 2016, 161, 3263-3268. [CrossRef]

29. Ansari, M.A.; Marchi, E.; Ramamurthy, N.; Klenerman, P. In vivo negative regulation of SARS-CoV-2 receptor, ACE2, by interferons and its genetic control [version 1; peer review: 1 approved with reservations]. Wellcome Open Res. 2021, 6, 47. [CrossRef]

30. Scagnolari, C.; Bitossi, C.; Viscido, A.; Frasca, F.; Oliveto, G.; Scordio, M.; Petrarca, L.; Mancino, E.; Nenna, R.; Riva, E.; et al. ACE2 expression is related to the interferon response in airway epithelial cells but is that functional for SARS-CoV-2 entry? Cytokine 2021, 140, 155430. [CrossRef] [PubMed]

31. National Center for Biotechnology. 2021. Available online: https://www.ncbi.nlm.nih.gov/snp/rs11322783?vertical_tab=true\# frequency_tab (accessed on 30 December 2021).

32. D’Ettorre, G.; Recchia, G.; Ridolfi, M.; Siccardi, G.; Pinacchio, C.; Innocenti, G.P.; Santinelli, L.; Frasca, F.; Bitossi, C.; Ceccarelli, G.; et al. Analysis of type I IFN response and T cell activation in severe COVID-19/HIV-1 coinfection: A case report. Medicine 2020, 99, e21803. [CrossRef]

33. Ji, D.; Zhang, D.; Xu, J.; Chen, Z.; Yang, T.; Zhao, P.; Chen, G.; Cheng, G.; Wang, Y.; Bi, J.; et al. Prediction for progression risk in patients with COVID-19 pneumonia: The CALL score. Clin. Infect. Dis. 2020, 71, 1393-1399. [CrossRef] [PubMed]

34. Kalinowski, A.; Galen, B.T.; Ueki, I.F.; Sun, Y.; Mulenos, A.; Osafo-Addo, A.; Clark, B.; Joerns, J.; Liu, W.; Nadel, J.A.; et al. Respiratory syncytial virus activates epidermal growth factor receptor to suppress interferon regulatory factor 1-dependent interferon-lambda and antiviral defense in airway epithelium. Mucosal Immunol. 2018, 11, 958-967. [CrossRef] [PubMed]

35. Davidson, S.; McCabe, T.M.; Crotta, S.; Gad, H.H.; Hessel, E.M.; Beinke, S.; Hartmann, R.; Wack, A. IFN $\lambda$ is a potent anti-influenza therapeutic without the inflammatory side effects of IFN $\alpha$ treatment. EMBO Mol. Med. 2016, 8, 1099-1112. [CrossRef] [PubMed]

36. Vanderheiden, A.; Ralfs, P.; Chirkova, T.; Upadhyay, A.A.; Zimmerman, M.G.; Bedoya, S.; Aoued, H.; Tharp, G.M.; Pellegrini, K.L.; Manfredi, C.; et al. Type I and type iii interferons restrict SARS-CoV-2 infection of human airway epithelial cultures. J. Virol. 2020, 94, e00985-20. [CrossRef] [PubMed]

37. Amodio, E.; Pipitone, R.M.; Grimaudo, S.; Immordino, P.; Maida, C.M.; Prestileo, T.; Restivo, V.; Tramuto, F.; Vitale, F.; Craxì, A.; et al. SARS-CoV-2 viral load, ifn $\lambda$ polymorphisms and the course of COVID-19: An observational study. J. Clin. Med. 2020, 9, 3315. [CrossRef]

38. Schönrich, G.; Raftery, M.J. Neutrophil extracellular traps go viral. Front. Immunol. 2016, 7, 366. [CrossRef]

39. Fuchs, T.A.; Abed, U.; Goosmann, C.; Hurwitz, R.; Schulze, I.; Wahn, V.; Weinrauch, Y.; Brinkmann, V.; Zychlinsky, A. Novel cell death program leads to neutrophil extracellular traps. J. Cell Biol. 2007, 176, 231-241. [CrossRef]

40. Thierry, A.R.; Roch, B. Neutrophil extracellular traps and by-products play a key role in COVID-19: Pathogenesis, Risk factors, and therapy. J. Clin. Med. 2020, 9, 2942. [CrossRef]

41. Barnes, B.J.; Adrover, J.M.; Baxter-Stoltzfus, A.; Borczuk, A.; Cools-Lartigue, J.; Crawford, J.M.; Daßler-Plenker, J.; Guerci, P.; Huynh, C.; Knight, J.S.; et al. Targeting potential drivers of COVID-19: Neutrophil extracellular traps. J. Exp. Med. 2020, 217, e20200652. [CrossRef]

42. Middleton, E.A.; He, X.Y.; Denorme, F.; Campbell, R.A.; Ng, D.; Salvatore, S.P.; Mostyka, M.; Baxter-Stoltzfus, A.; Borczuk, A.C.; Loda, M.; et al. Neutrophil extracellular traps contribute to immunothrombosis in COVID-19 acute respiratory distress syndrome. Blood 2020, 136, 1169-1179. [CrossRef]

43. Masso-Silva, J.A.; Moshensky, A.; Lam, M.; Odish, M.; Patel, A.; Xu, L.; Hansen, E.; Trescott, S.; Nguyen, C.; Kim, R.; et al. Increased peripheral blood neutrophil activation phenotypes and NETosis in critically ill COVID-19 patients: A case series and review of the literature. Clin. Infect. Dis. 2021, 437. online ahead of print. 
44. Arcanjo, A.; Logullo, J.; Menezes, C.; de Souza Carvalho Giangiarulo, T.C.; Dos Reis, M.C.; de Castro, G.; da Silva Fontes, Y.; Todeschini, A.R.; Freire-de-Lima, L.; Decoté-Ricardo, D.; et al. The emerging role of neutrophil extracellular traps in severe acute respiratory syndrome coronavirus 2 (COVID-19). Sci. Rep. 2020, 10, 19630. [CrossRef]

45. Palermo, E.; di Carlo, D.; Sgarbanti, M.; Hiscott, J. Type i interferons in COVID-19 pathogenesis. Biology 2021, 10, 829. [CrossRef] [PubMed]

46. Jafarzadeh, A.; Nemati, M.; Saha, B.; Bansode, Y.D.; Jafarzadeh, S. Protective potentials of type III interferons in COVID-19 patients: Lessons from differential properties of type I- and III interferons. Viral Immunol. 2021, 34, 307-320. [CrossRef] [PubMed]

47. Chua, R.L.; Lukassen, S.; Trump, S.; Hennig, B.P.; Wendisch, D.; Pott, F.; Debnath, O.; Thürmann, L.; Kurth, F.; Völker, M.T.; et al. COVID-19 severity correlates with airway epithelium-immune cell interactions identified by single-cell analysis. Nat. Biotechnol. 2020, 38, 970-979. [CrossRef] [PubMed]

48. Liao, M.; Liu, Y.; Yuan, J.; Wen, Y.; Xu, G.; Zhao, J.; Cheng, L.; Li, J.; Wang, X.; Wang, F.; et al. Single-cell landscape of bronchoalveolar immune cells in patients with COVID-19. Nat. Med. 2020, 26, 842-844. [CrossRef] [PubMed]

49. Lachowicz-Scroggins, M.E.; Dunican, E.M.; Charbit, A.R.; Raymond, W.; Looney, M.R.; Peters, M.C.; Gordon, E.D.; Woodruff, P.G.; Lefrançais, E.; Phillips, B.R.; et al. Extracellular DNA, neutrophil extracellular traps, and inflammasome activation in severe asthma. Am. J. Resp. Crit. Care Med. 2019, 199, 1076-1085. [CrossRef]

50. Blazek, K.; Eames, H.L.; Weiss, M.; Byrne, A.J.; Perocheau, D.; Pease, J.E.; Doyle, S.; McCann, F.; Williams, R.O.; Udalova, I.A. IFN- $\lambda$ resolves inflammation via suppression of neutrophil infiltration and IL-1 $\beta$ production. J. Exp. Med. 2015, 212, 845-853. [CrossRef]

51. Nick, J.A.; Caceres, S.M.; Kret, J.E.; Poch, K.R.; Strand, M.; Faino, A.V.; Nichols, D.P.; Saavedra, M.T.; Taylor-Cousar, J.L.; Geraci, M.W.; et al. Extremes of Interferon-stimulated gene expression associate with worse outcomes in the acute respiratory distress syndrome. PLoS ONE 2016, 11, e0162490. [CrossRef]

52. Malcolm, K.C.; Kret, J.E.; Young, R.L.; Poch, K.R.; Caceres, S.M.; Douglas, I.S.; Coldren, C.D.; Burnham, E.L.; Moss, M.; Nick, J.A. Bacteria-specific neutrophil dysfunction associated with interferon-stimulated gene expression in the acute respiratory distress syndrome. PLOS ONE 2011, 6, e21958. [CrossRef]

53. Broggi, A.; Tan, Y.; Granucci, F.; Zanoni, I. IFN- $\lambda$ suppresses intestinal inflammation by non-translational regulation of neutrophil function. Nat. Immunol. 2017, 18, 1084-1093. [CrossRef]

54. Severe COVID-19 GWAS Group; Ellinghaus, D.; Degenhardt, F.; Bujanda, L.; Buti, M.; Albillos, A.; Invernizzi, P.; Fernández, J.; Prati, D.; Baselli, G.; et al. Genomewide association study of severe COVID-19 with respiratory failure. N. Engl. J. Med. 2020, 383, 1522-1534. [CrossRef] [PubMed]

55. Mousa, M.; Vurivi, H.; Kannout, H.; Uddin, M.; Alkaabi, N.; Mahboub, B.; Tay, G.K.; Alsafar, H.S.; UAE COVID-19 Collaborative Partnership. Genome-wide association study of hospitalized COVID-19 patients in the United Arab Emirates. EBioMedicine 2021, 74, 103695. [CrossRef] [PubMed]

56. Li, Y.; Ke, Y.; Xia, X.; Wang, Y.; Cheng, F.; Liu, X.; Jin, X.; Li, B.; Xie, C.; Liu, S.; et al. Genome-wide association study of COVID-19 severity among the Chinese population. Cell Discov. 2021, 7, 76. [CrossRef] [PubMed] 